\title{
Implementation of warm-cloud processes in a source-oriented WRF/Chem model to study the effect of aerosol mixing state on fog formation in the Central Valley of California
}

\author{
H.-H. Lee et al.
}

Correspondence to: S.-H. Chen (shachen@ucdavis.edu)

The copyright of individual parts of the supplement might differ from the CC-BY 3.0 licence. 
(a)

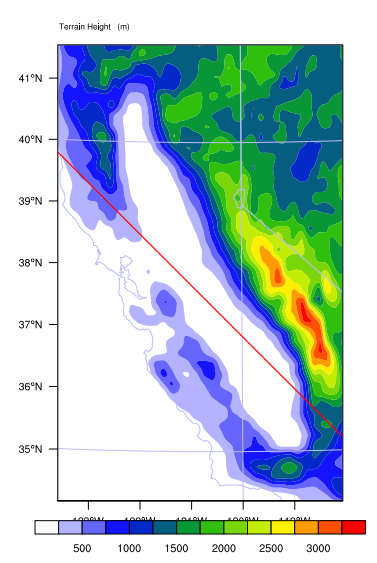

(c)

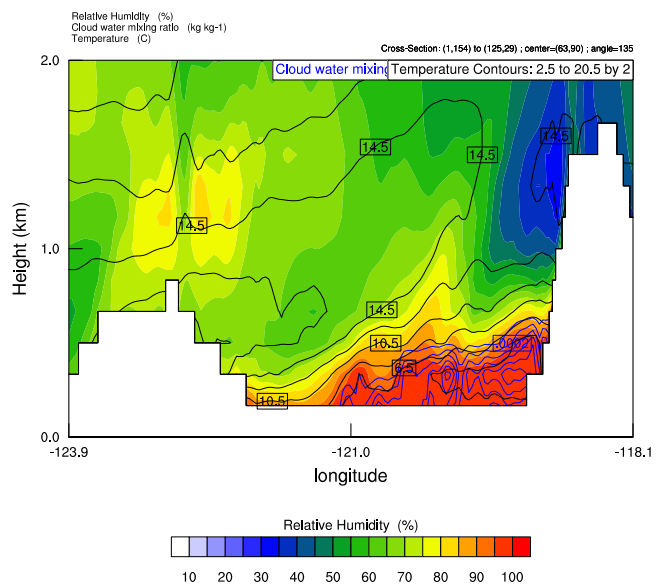

(b)

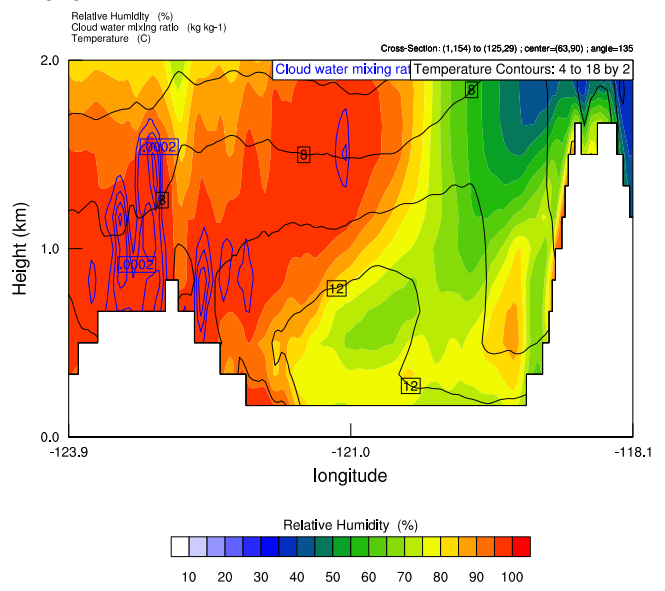

(d)

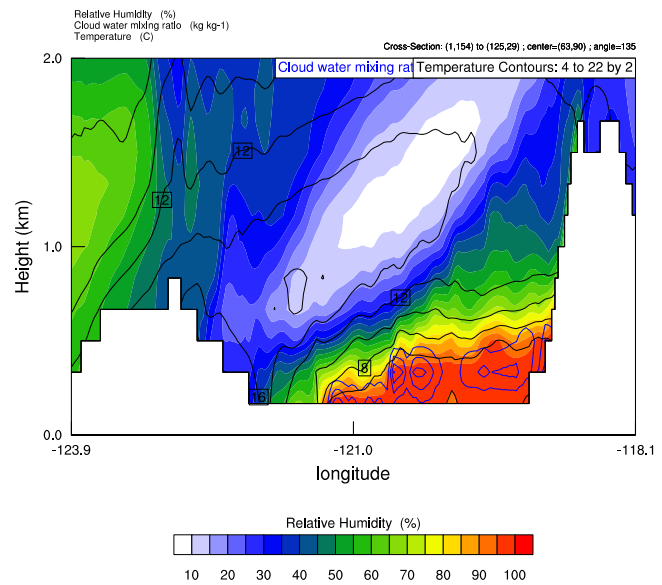

Figure S1. The vertical cross section of relative humidity (shaded color, \%), cloud liquid water mass (blue lines, $\mathrm{kg} \mathrm{kg}^{-1}$ ), and temperature (black lines, degree $\mathrm{C}$ ) at 0000 UTC (4 PM local time) (b) 14 January, (c) 17 January, and (d) 19 January, along the red line in (a). The results are from S_ARon_CRmod. 
(a)

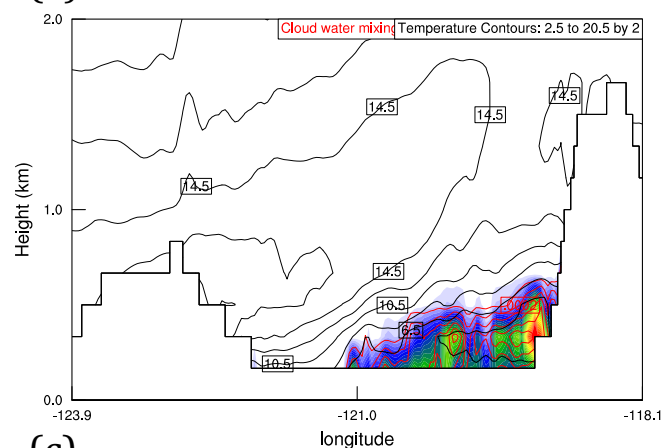

(c)

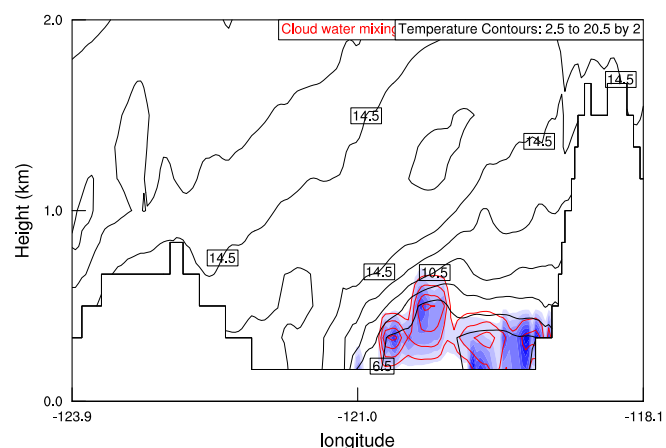

(e)

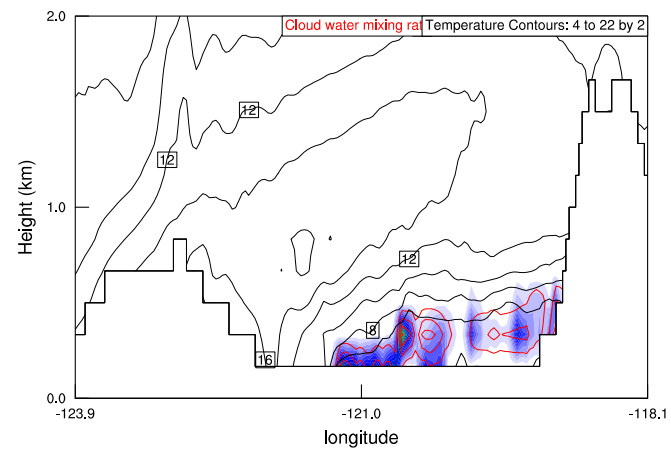

(b)

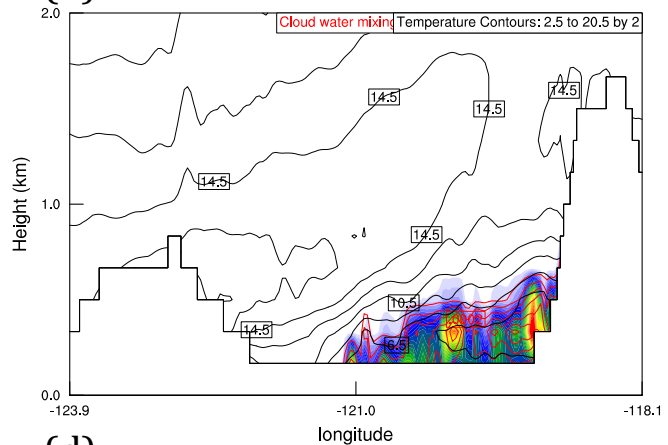

(d)

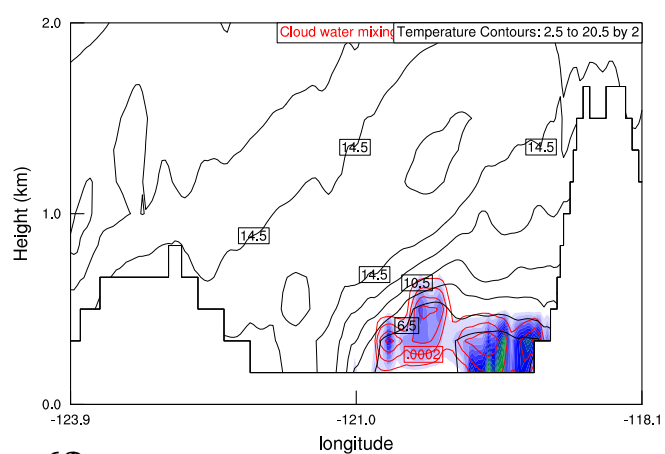

(f)

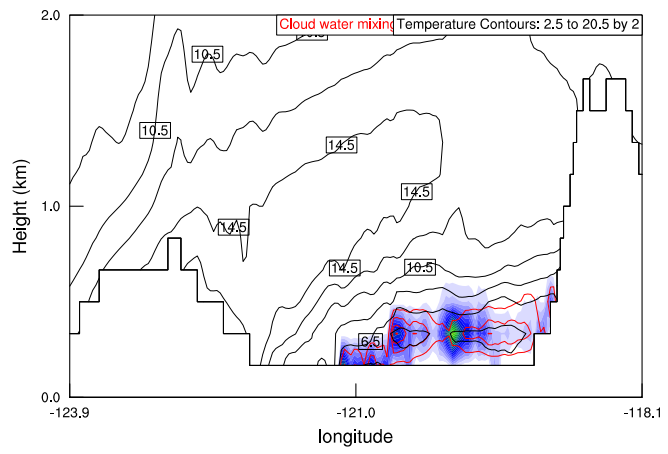

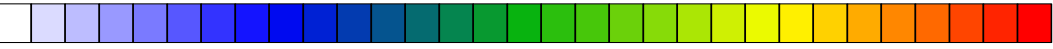

1004007001000130016001900220025002800

Figure S2. The vertical cross section of CCN number concentration, cloud liquid water mass (red lines, $\mathrm{kg} \mathrm{kg}^{-1}$ ), and temperature (black lines, degree $\mathrm{C}$ ) at 0000 UTC (4 PM local time) (a, b) 17 January, (c, d) 18 January, and (d, e) 19 January, along the red line in Fig. S1 (a). (a), (c) and (e) are from S_ARon_CRmod. (b), (d) and (f) are from I_ARon_CRmod. 